\title{
Does telework weaken urban structure-travel relationships?
}

\section{Erik Elldér}

University of Gothenburg

erik.ellder@geography.gu.se

Abstract: This paper investigates whether urban structure influences daily travel behavior differently when people telework in urban contexts. Regression models are applied to address whether and to what extent travel is associated with various measures of urban structure and key destination accessibility relative to the home location in Gothenburg, Sweden. The analysis treats groups of workers defined by teleworking practices. Micro-level data from the Swedish National Travel Survey 2011 capture individual travel behavior, while Swedish register data on the location of all firms and individuals combined with a GIS-based tool that measures travel times by car or public transport capture urban structure. Results indicate that telework weakens the relationship between urban structure and travel. Regression models of travel distance and time as functions of various geographical aspects of residential location display a much better fit for those not teleworking regularly. Telework allows various mobility strategies that together foster more spatially heterogeneous daily travel behavior, more dependent on personal attributes than on the home location relative to the workplace. Planners and policymakers should monitor whether the number of teleworkers continues to increase. If so, traditional distance- and location-based models and policies for predicting and planning transport may prove less accurate and effective than currently assumed.

\section{Article history:}

Received: May 19, 2014

Received in revised form: March

9, 2015

Accepted: March 15, 2015

Available online: August 20,

2015

\section{Introduction}

Over two decades after the launching of the World Wide Web, it is clear that initial expectations that information and communication technologies (ICT) would have a strong substitution effect, replacing location-based with ICT-based activities and thus substantially reducing overall travel, have not been realized (Andreev, Salomon, and Pliskin 2010; Mokhtarian and Tal 2013). Many scholars nevertheless argue that increased ICT access and use have modified traditional patterns of activity and travel in time and space (Couclelis 2000; Kwan, Dijst, and Schwanen 2007; Lenz and Nobis 2007; Lyons 2009; Van Wee, Geurs, and Chorus 2013). For example, ICT might relax many traditional spatiotemporal constraints (e.g., commuting to a specific workplace at a specific time), freeing up time for traveling to other activities and possibly stimulating new destination choices based more on personal preferences

Copyright 2015 Erik Elldér

http://dx.doi.org/10.5198/jtlu.2015.719

ISSN: 1938-7849 | Licensed under the Creative Commons Attribution - Noncommercial License 3.0

The Journal of Transport and Land Use is the official journal of the World Society for Transport and Land Use (WSTLUR) and is published and sponsored by the University of Minnesota Center for Transportation Studies. 
than geographical proximity. These views clearly assert a change in the role of urban spatial structure and physical access in forming everyday travel. However, few empirical studies have sought to understand how ICT affects accessibility (Lu, Chorus, and Van Wee 2012; Van Wee, Geurs, and Chorus 2013) or explore whether ICT use reduces the importance of proximity as an organizing principle of traveling (Kwan 2002). This is an important issue. Results could, for example, help inform ongoing discussions on whether daily travel is becoming less location-based (Elldér 2014a; Kwan and Weber 2003; Miller 2007) and have implications for planning and policy in the future, not least from a sustainability perspective, including efforts to control urban and regional location structures (Couclelis 2000; Helling and Mokhtarian 2001). Couclelis (2000, 353), for example, argues "that because of the growing spatiotemporal plasticity and fragmentation of activities, planners have less control than ever before on what activities take place where (and when).” Traditional planning and design policies of densifying metropolitan areas to reduce travel distances might be less effective as access to and use of ICT increase, affording new opportunities to organize daily activities in time and space.

This paper advances these discussions by investigating whether urban structure and physical access to destinations relative to home influence travel behavior differently in an urban context when people telework. If so, that might indicate to what extent and how ICT affects daily travel and, in the long run, the location patterns of urban activities as well. Work-related travel is generally related more to spatial circumstances than are other trips (Elldér 2014b; Næss 2005), as workplaces in many urban areas are geographically concentrated in inner cities and industrial areas and where and when wage labor is performed is determined largely by the employer. Work is also the activity most likely to bind other daily activities in time and space (Schwanen, Kwan, and Ren 2008). One plausible hypothesis could therefore be that the ability to telework (often by using ICT) relaxes the daily spatiotemporal constraints and erodes the strong relationships between urban structure and daily travel behavior on workdays. The opportunity to telework may enable people to decide more freely where and when to travel to work or, if preferred, to work at home. The time saved could then be used for other (potentially travel-demanding) activities. Put differently, when the spatial patterns of daily travel and activities are not anchored to a work location, this might allow a range of mobility strategies, possibly contributing to increasingly spatially heterogeneous traveling based more on individual needs than urban structure. Against this background, it is important to investigate whether teleworkers use the potential to move more freely and are less dependent on the patterns of urban location and distances. Furthermore, though telework has yet to reach the initially expected high levels and has remained at modest levels for several years, there has been a rapid increase in recent years in Sweden and several other countries. According to the Swedish National Travel Survey, 17.4 percent of Swedish workers reported teleworking regularly in $2011^{1}$, versus 9.8 percent in 2005-06 (Vilhelmson and Thulin 2015). Apart from increasing the relevance of the research issue, this increase allows us to go beyond many previous studies of telework and travel behavior often criticized for their small samples, unrepresentative of an entire workforce (Andreev, Salomon, and Pliskin 2010; Mokhtarian and Tal 2013).

The precise aim of this paper is to examine how urban structure and physical access to key destinations relate to the daily travel behavior of teleworkers versus non-teleworkers in the urban region of Gothenburg, Sweden. This is done mainly by using regression models to address whether and to what extent variation in worker travel behavior is associated with various measures of urban structure and physical access to key destinations relative to the home location. The analysis is performed for different groups of workers defined by their actual teleworking practices. Data are extracted from a unique combination of geo-coded micro-level data: Data from the Swedish National Travel Survey conducted in 2011 capture individual travel behavior and teleworking practices, and Swedish register data on the location of all firms and individuals combined with a GIS-based tool measuring travel times by car or

${ }^{1}$ Note that the estimates from the National Travel Survey are to be seen more as an indication since "regularly" is not defined quantitatively. The questions concerning telework are, however, asked identically in each survey and 19.7 percent reported teleworking regularly in the 2012 survey. The definition of telework is further discussed in Section 3.3.1 
public transport (PT) capture the patterns of urban location relative to where workers live. The high resolution of these data advances research in this field, which is often characterized by high levels of aggregation and small datasets.

The paper is structured as follows. This introduction is followed by a review of previous literature relevant to the aim of this study. The third section presents the study area, data sources, and methods. The results are presented and analyzed in the fourth section, and the results are discussed and the conclusion presented in the fifth and final section.

\section{$2 \quad$ Literature review}

Daily travel behavior can be seen as the result of a strategy by which people spatially match their demand for activities against the supply of facilities in order to fulfill the needs and wants of their daily lives (Jones 1983). Given time constraints, the spatial dispersion and physical accessibility of facilities relative to where people live are central determinants of travel behavior. A growing literature examines such relationships between land use and travel (e.g., Boarnet 2011; Ewing and Cervero 2001, 2010; Næss 2013; Stead and Marshall 2001), generally concluding, for example, that people living in areas that are more densely populated and land-use diversified (Cervero and Kockelman 1997), near jobs (Cervero 1989), and more accessible to city centers (Næss 2005) commute shorter distances, travel less daily in general, and use more sustainable transportation modes.

Though such studies seldom take ICT use and access into account, the impact of ICT on activity and travel has received considerable attention in recent decades from other parts of the transportation literature (Andreev, Salomon, and Pliskin 2010; Salomon 1986). Empirical studies have traditionally been concerned with the relationships between ICT use and travel demand, i.e., whether ICT use substitutes for, complements, and/or generates travel (Salomon 1986). However, recent studies have also considered how ICT use modifies and/or fragments travel and activity participation (e.g., Lenz and Nobis 2007) and directly affects route choices (e.g., Farag and Lyons 2010). A central conclusion of this literature is that the fast growth of ICT use has not resulted in any extensive overall net decrease in daily travel (i.e., substitution). Some authors suggest that increased ICT use may have contributed to the saturation of daily travel observed in many countries lately (Frändberg and Vilhelmson 2014; Vilhelmson and Thulin 2008). The decrease of daily travel in younger cohorts may, for example, be linked to increasing use of ICT. However, besides concluding that ICT increases the underlying complexity of travel and destination choices, it is difficult to make general statements regarding how ICT affects travel. Mokhtarian and Tal (2013) describes these complex interrelationships as an "intricate tapestry" in which the effects range from the direct (e.g., information about a given trip) to the collateral in the short- (e.g., activity participation), medium- (e.g., car ownership), and long-term (e.g., migration). Van Wee, Geurs, and Chorus (2013) provides a conceptual overview of how this-in Mokhtarian and Tal's words - "tapestry of relationships" could shape people's accessibility in various ways. The central theme is ICT's potential to ease traditional spatiotemporal constraints, including by reducing travel resistance, allowing activities to be carried out at different times of the day, better matching activities and facilities, and substituting virtual for physical access.

Many empirical studies focusing on the implications of telework for travel demand have been carried out over the years (Andreev, Salomon, and Pliskin 2010). Based on these studies, it is safe to say that telework, on average, reduces travel in the very short term. However, it is more difficult to draw general conclusions in the longer term since telework, for example, might result in residential relocation to areas with higher travel demand (Mokhtarian, Collantes, and Gertz 2004) as well as saving time to use for other potentially travel-based activities (Hopkinson and James 2003). Some studies have focused more on how telework modifies daily travel patterns and make more detailed comparisons of teleworkers' 
spatial travel patterns with those of non-teleworkers (or with their own on non-telework days).

Though such studies seldom ask whether telework affects urban form-travel relationships, an overall and important conclusion of such studies is that there often are significant differences in the spatial dispersion of daily travel and destination choices. Mokhtarian and Varma (1998), for example, compared the travel behavior of center-based telecommuting on telecommuting and non-telecommuting days in California, and found that the distance traveled for non-work purposes declined on telecommuting days. Trip rates increased, however, since workers often went home from the telecenter on their lunches. Though such an observation is expected since commuting often constitutes most traveling on a workday, it has important implications for the research question asked here. If telework makes little difference to the spatial patterns of daily travel, there would also most likely be few differences in how travel relates to urban form. The effect of the home location on travel behavior, however, was not controlled for by Mokhtarian and Varma (1998). A similar study, Saxena and Mokhtarian (1997), also includes spatial information about trip destinations in relation to the home and work locations in the analysis. An interesting finding, that may support the hypothesis of weakened urban structure-travel relationships due to telework, was that destinations on regular commuting days were mainly planned toward the work location while destinations on telecommuting days were spread in all directions. Another relevant study is that of Pendyala, Goulias, and Kitamura (1991), which noted that the daily mobility of teleworkers is less spatially dispersed than that of commuters to a regular workplace. This could contradict the hypothesis that teleworkers' daily travel is more spatially heterogeneous. On the other hand, Pendyala, Goulias, and Kitamura (1991) do not take into account whether or to what extent traveling is related to urban structure. An important aspect to bear in mind when drawing conclusions from this literature is that, given the fast development of ICT and telework in recent years, many of these studies might be somewhat outdated. Many previous empirical studies are also criticized because of data deficiencies (i.e., small and non-representative samples) (Andreev, Salomon, and Pliskin 2010; Mokhtarian and Tal 2013). Since telework has not been that widespread, it has been difficult to achieve representative samples of whole working populations when collecting data on individuals' daily travel. Many studies have surveyed single companies in which a relatively large share of workers can telework (e.g., in telecom industries).

In conclusion, there is little empirical evidence whether currently accepted relationships between the spatial patterns of urban location and travel differ between teleworkers and non-teleworkers. Many authors have argued theoretically that this is the case since ICT and telework can relax spatiotemporal constraints. This may reduce the importance of physical access and urban form relative to individual choice for daily travel behavior. As is clear from the literature review, this hypothesis remains to be tested empirically using recent and adequate data, providing the main justification and contribution of this paper.

\section{Study area, data, and methods}

\subsection{Study area}

The study is set in the greater Gothenburg metropolitan area, defined as Gothenburg municipality and the adjacent municipalities of Kungälv, Partille, Härryda, Öckerö, Ale, Lerum, Mölndal, and Kungsbacka (see Figure 1). Gothenburg is the second largest city in Sweden with approximately 550,000 inhabitants at the time of study. The entire study area, which is home to 840,000 individuals, includes a well-organized transportation network with main roads, regional trains, and a tram network in the city of Gothenburg.

Though many cities have experienced decentralization, resulting in more polycentric urban struc- 
tures, Gothenburg has remained fairly monocentric, with 75 percent of jobs in the study area being located in urban Gothenburg. In addition, there are industrial areas in the semi-periphery of Gothenburg and several local centers (e.g., Kungälv and Kungsbacka) outside the main urban area where access to services, retail, and PT is relatively good.

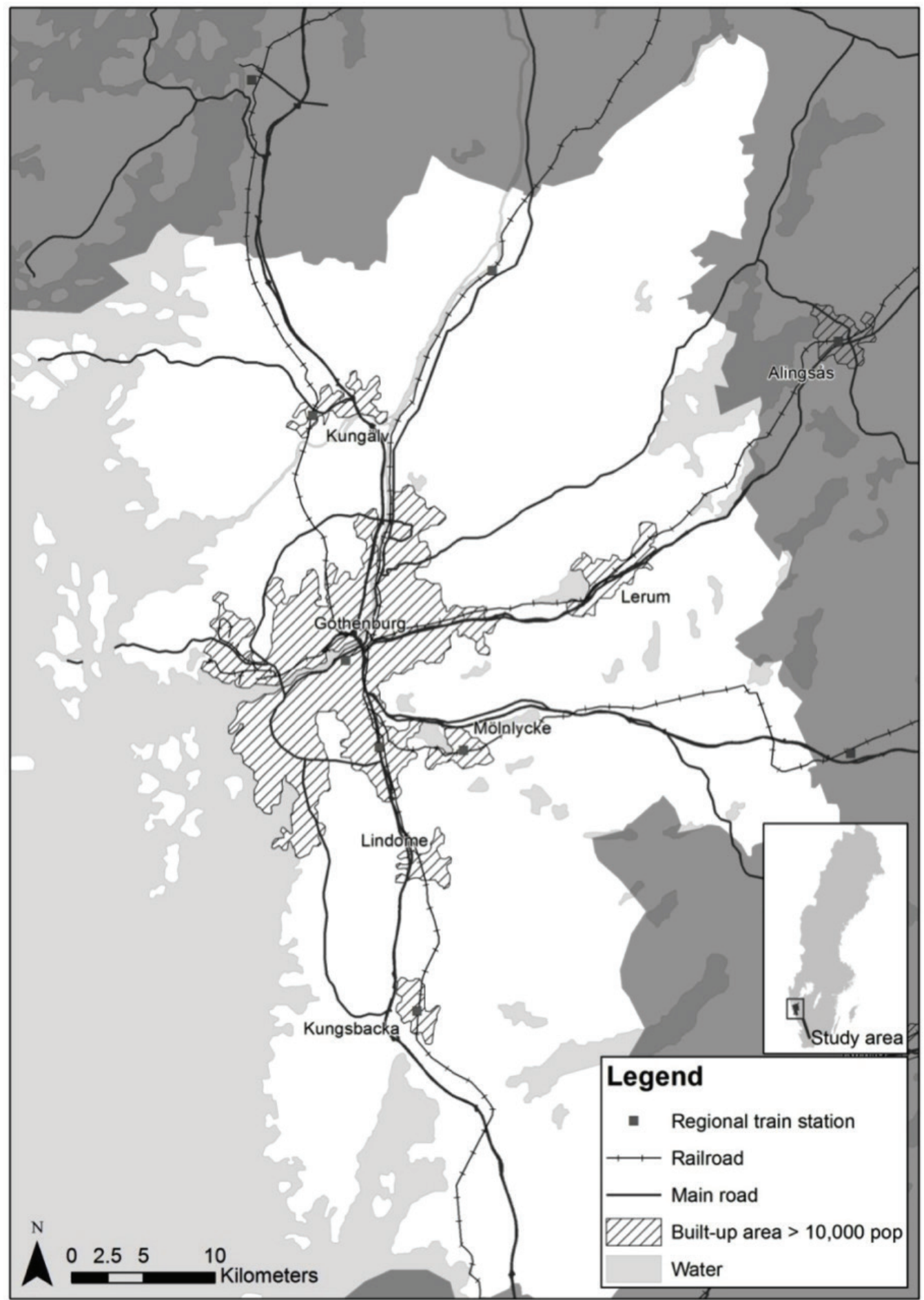

Figure 1: Map of the study area 


\subsection{Complementary data sources}

The main data come from the Swedish National Travel Survey (RES) carried out in 2011 (Trafikanalys 2012). This survey gathered data on the everyday traveling of a large randomized sample of the Swedish population. Every person surveyed was assigned a random measurement day. All relocations outside the respondent's dwelling on this day were recorded using travel diaries. The respondents also answered questions concerning various background conditions that may affect their travel behavior. Unlike many other national travel surveys, RES also includes several questions concerning ICT and telework practices. The response rate was 47 percent, for a total of 7392 respondents living in the study area.

Two databases were used to define the variables describing urban form. The Geographical Individual Longitudinal Database for Analysis (GILDA) comprises the Swedish official register of geocoded micro-data for every individual and firm in the study area in 2010. Data from official Swedish educational, income, employment, health insurance, and population registers are integrated into this database (SCB 2011). A key aspect of GILDA is that it includes geographical coordinates for both firms and individual homes (with a 100-meter resolution). GILDA was complemented with a GIS-based tool that measures accessibility by car and PT in the study area (Larsson, Elldér, and Vilhelmson 2014). The tool was used to define independent urban structural variables by assessing travel times by car or PT from the respondents' homes in RES residential locations to various key destinations defined according to GILDA.

\subsection{Preparing data for analysis and defining variables}

\subsubsection{Defining groups for comparison}

A key methodological procedure was to define groups of respondents for comparison based on their teleworking practices. Two survey questions were used to create these comparison groups: 1) "Do you telework regularly?" and 2) "You stated earlier that on the day of the survey, you undertook paid work at a location other than your normal workplace. Was that telework?" The respondent was told that telework in this case referred to work sometimes performed at any place other than the usual workplace. Note that this definition also includes part-day teleworking. The respondent was also told that it was not considered telework to "work on your way to or from work (e.g., reading a report on the bus)," "bring your work home after working hours," "go on an errand during your work," or "temporarily work at home due to a sick child, etc." Also, workers with "mobile" workplaces (i.e., no fixed location/flexible locations every day) are not included.

Note that the respondents were not given any quantitative definition of "regularly" in the first question. However, the second question, asking about teleworking on the survey day, defines teleworking more strictly and better captures the differences in urban form-travel relationships possibly attributable to telework. It is also important to examine the group that teleworks regularly, though not on the survey day, to capture the entire telework population. Teleworking is not necessarily done every day. ${ }^{2}$ Furthermore, the possibility of teleworking can be understood as a mobility strategy that could, for example, enable people to live more inaccessibly, changing the relationship between urban structure and travel habits. This is also important for validity reasons, because those who are able to telework can generally be expected to possess greater mobility resources (e.g., due to higher income) and hence be less constrained by urban spatial structure. In addition, comparing active teleworkers with regular teleworkers who did not telework on the survey day increases the validity of the results, as it more closely lets us examine whether it is teleworking that makes the difference, if any. However, as further discussed in Section 3.3.3, it is important to note that due to the cross-sectional nature of this study, the comparison groups

${ }^{2}$ It would also not be defined as telework to work from home every day, as the home would then constitute the regular workplace, for example, in the case of farmers. 
are not equal in all regards except teleworking practices.

Only respondents who performed wage labor on the survey day and who stated whether or not they teleworked on the survey day were selected for analysis. Following this procedure, a total of 2500 individuals were selected for analysis from RES. ${ }^{3}$ A total of 536 (23.1 percent) individuals reported teleworking regularly, of whom 180 stated that they teleworked on the survey day (see Table 1). Note that almost all of the teleworkers who teleworked on the survey day (97 percent) reported teleworking from home.

\subsubsection{Dependent variable}

This study operationalizes travel behavior as two dependent variables: total distance traveled and time spent traveling on the survey day. By focusing on total travel, possible rebound effects on the survey day are captured by the dependent variables. Total daily distance traveled is the main dependent variable. Distance is central to sustainable mobility (Banister 2011); for example, shorter trips increase the opportunity to use sustainable travel modes such as walking and cycling. Often highly correlated with travel distance, travel time is also related to environmental issues. Furthermore, travel time is also directly linked to workers' quality of life and stress (Wener et al. 2003).

Table 1 presents descriptive statistics for the dependent variables. The regular teleworkers traveled farther and for a longer time on the survey day than did non-teleworkers. However, looking more closely at the group of regular teleworkers reveals that those teleworking on the survey day traveled a shorter distance than did those who did not. Meanwhile, those who did not telework on the survey day spent less time traveling. Furthermore, note that the standard deviations in the dependent variables for the teleworkers are larger than for the non-teleworkers. The larger variability in travel behavior could, however, be consistent with the hypotheses that telework weakens urban structure-travel relationships. When people are able to telework daily, spatiotemporal constraints might be relaxed and result in larger variability in daily travel. For example, some workers might spend time at their regular workplace only part of the day, and some may work from home during weekends saving time for leisure activities on weekdays. There were no outliers in regard to very long distance travel present in the data.

Note that the dependent variables were transformed using natural logarithms to produce a normal distribution before running the models since the regression models used (described in Section 3.4) assume the dependent variables to be normally distributed around their means. Respondents who did not travel during the survey day were therefore not included in the final models. However, only 2.3 percent of the respondents in the sample reported no trips and they were not overrepresented in any of the groups defined for comparison (see Table 1).

\subsubsection{Individual control variables}

Several individual control variables were constructed from the RES database. These comprise standard socio-demographic variables previously found to be important determinants of travel behavior (see Table 1). These variables are used mainly to improve the validity of the analysis. Base models are first fitted with individual control variables before adding urban form variables. This procedure confirms that statistically significant correlations between travel behavior and urban structure remain after controlling for the individual covariates. The empirical analysis procedure is further described in Sections 3.4 and 4.

A fairly expected picture appears when comparing how the individual characteristics are distributed within the groups (Helminen and Ristimäki 2007; Vilhelmson and Thulin 2001). Respondents who telework regularly have higher incomes and education and are more likely employed in the advanced service sector compared with those not regularly teleworking; as well, larger shares have access to a car,

\footnotetext{
${ }^{3} 175$ respondents did not state whether or not they teleworked and were therefore excluded from the analysis.
} 
live with their children, and are in midlife. When comparing regular teleworkers based on whether or not they teleworked on the survey day, there are much smaller differences. However, respondents who teleworked on the survey day are more likely to be male, employed in advanced services, and surveyed on a weekend. As discussed above, this reflects the cross-sectional nature of the data not allowing for conclusions on the direct causal effects of telework. For comparative reasons, Table 1 also includes descriptives for the total population for variables available in the official Swedish registers. 
Table 1: Descriptive statistics for individual variables

\begin{tabular}{|c|c|c|c|c|c|}
\hline & \multirow[t]{4}{*}{ Total population $^{\mathrm{a}}$} & \multicolumn{4}{|c|}{ Regular teleworker } \\
\hline & & \multirow[t]{3}{*}{ No } & \multicolumn{3}{|c|}{ Yes } \\
\hline & & & & \multicolumn{2}{|c|}{ Teleworked on survey day } \\
\hline & & & Total & Yes & No \\
\hline Total (n) & 403,316 & $1789(76.9 \%)$ & $536(23.1 \%)$ & $180(33.7 \%)$ & $354(66.3 \%)$ \\
\hline No trips during survey day (n) & - & $37(2.1 \%)$ & $16(3.0 \%)$ & $4(2.2 \%)$ & $12(3.4 \%)$ \\
\hline Survey day on a weekday & - & $1652(92.3 \%)$ & $501(93.5 \%)$ & $154(85.6 \%)$ & $345(97.5 \%)$ \\
\hline Reported a commuting trip on survey day & - & $1594(89.1 \%)$ & $416(77.6 \%)$ & $109(60.6 \%)$ & $305(86.2 \%)$ \\
\hline \multicolumn{6}{|l|}{ Travel distance $(\mathrm{km})$} \\
\hline Mean & - & 46.44 & 60.83 & 53.74 & 63.96 \\
\hline Std. deviation & - & 72.19 & 115.54 & 86.93 & 127.47 \\
\hline LN (mean) & - & 3.32 & 3.45 & 3.26 & 3.53 \\
\hline Std. deviation & - & 1.11 & 1.23 & 1.34 & 1.16 \\
\hline Missing & & 244 & 49 & 20 & 29 \\
\hline \multicolumn{6}{|l|}{ Travel time (min) } \\
\hline Mean & - & 87.20 & 100.81 & 103.01 & 99.25 \\
\hline Std. deviation & - & 68.93 & 94.77 & 106.68 & 88.28 \\
\hline LN (mean) & - & 4.28 & 4.40 & 4.33 & 4.43 \\
\hline Std. deviation & - & 0.69 & 0.74 & 0.85 & 0.67 \\
\hline Missing & & 102 & 16 & 5 & 11 \\
\hline \multicolumn{6}{|l|}{ Income (SEK thousands) } \\
\hline Mean & 29.67 & 32.82 & 44.50 & 44.10 & 44.68 \\
\hline Std. deviation & 23.60 & 14.53 & 20.08 & 19.70 & 20.34 \\
\hline Missing & & 175 & 33 & 10 & 23 \\
\hline \multicolumn{6}{|l|}{ Sex } \\
\hline Male & $206,387(51.2 \%)$ & $897(50.1 \%)$ & $280(52.2 \%)$ & $110(61.1 \%)$ & $168(47.5 \%)$ \\
\hline Female & $196,929(48.8 \%)$ & $892(49.9 \%)$ & $256(47.8 \%)$ & $70(38.9 \%)$ & $186(52.5 \%)$ \\
\hline Missing & & - & - & - & - \\
\hline \multicolumn{6}{|l|}{ Car access } \\
\hline Yes & - & $1397(78.1 \%)$ & $478(89.2 \%)$ & $160(88.9 \%)$ & $316(89.3 \%)$ \\
\hline No & - & $391(21.9 \%)$ & $58(10.8 \%)$ & $20(11.1 \%)$ & $38(10.7 \%)$ \\
\hline Missing & & 1 & - & - & - \\
\hline \multicolumn{6}{|l|}{ Education } \\
\hline$<$ Upper secondary school & $40,222(10.0 \%)$ & $220(12.3 \%)$ & $21(3.9 \%)$ & $7(3.9 \%)$ & $14(4.0 \%)$ \\
\hline Upper secondary school & $173,747(43.1 \%)$ & $782(43.7 \%)$ & $116(21.7 \%)$ & $37(20.6 \%)$ & $79(22.4 \%)$ \\
\hline Higher education $\leq 2$ yrs & $67,052(16.6 \%)$ & $277(15.5 \%)$ & $108(20.2 \%)$ & $33(18.3 \%)$ & $75(21.2 \%)$ \\
\hline Higher education $>2$ yrs & $120,197(29.8 \%)$ & $488(27.3 \%)$ & $290(54.2 \%)$ & $103(57.2 \%)$ & $185(52.4 \%)$ \\
\hline Missing & & 22 & 1 & - & 1 \\
\hline \multicolumn{6}{|l|}{ Employment sector } \\
\hline Advanced services $^{\mathrm{b}}$ & $53,531(13.3 \%)$ & $211(11.8 \%)$ & $124(23.2 \%)$ & $53(29.4 \%)$ & $71(20.1 \%)$ \\
\hline Other sectors & $349,785(86.7 \%)$ & $1571(88.2 \%)$ & $411(76.7 \%)$ & $127(70.6 \%)$ & $282(79.9 \%)$ \\
\hline Missing & & 7 & 1 & - & 1 \\
\hline \multicolumn{6}{|l|}{ Household } \\
\hline Single $^{c}$ & - & $351(19.9 \%)$ & $72(13.5 \%)$ & $27(15.0 \%)$ & $45(12.7 \%)$ \\
\hline Two adults only & - & $646(36.5 \%)$ & $156(29.2 \%)$ & $54(30.0 \%)$ & $101(28.6 \%)$ \\
\hline Two adults or single with children $\leq 18$ yrs & - & $771(43.6 \%)$ & $307(57.4 \%)$ & $99(55.0 \%)$ & $207(58.6 \%)$ \\
\hline Missing & & 21 & 1 & - & 1 \\
\hline \multicolumn{6}{|l|}{ Age } \\
\hline$<31$ yrs & $94333(23.4 \%)$ & $349(19.5 \%)$ & $43(8.0 \%)$ & $18(10.0 \%)$ & $25(7.1 \%)$ \\
\hline $31-54$ yrs & $230678(57.2 \%)$ & $997(55.7 \%)$ & $383(71.5 \%)$ & $122(67.8 \%)$ & $259(73.2 \%)$ \\
\hline$>54$ yrs & $78305(19.4 \%)$ & $443(24.8 \%)$ & $110(20.5 \%)$ & $40(22.2 \%)$ & $70(19.8 \%)$ \\
\hline Missing & & - & - & - & - \\
\hline
\end{tabular}

a Based on GILDA data of the total population engaged in labor and residing within the study area. The variables describing daily travel, telework, and car access are not available in GILDA. The household variable is not comparable.

${ }^{b}$ Based on the 2007 Swedish standard industrial classification in which the main groups are: J, information and communication; K, financial and insurance activities; and M, professional, scientific, and technical activities.

${ }^{\mathrm{c}}$ Also includes single adults still living with their parents. 


\subsubsection{Urban structure variables}

Most previous studies of land use-travel interactions have focused on neighborhood-scale land-use characteristics of limited geographical scale (e.g., population density or street pattern within a census tract). However, many authors have recently demonstrated that regional land-use variables (e.g., distance to city center) tend to explain more variation in daily distance traveled than do neighborhood-scale variables (Boarnet 2011; Ewing and Cervero 2010; Næss 2011). A common issue in this context is that various independent variables capturing the geographical context of the residential location are often highly correlated, making it difficult to evaluate which variables causally influence travel. Distance to the city center, for example, could be thought of as a proxy for other important aspects of the built environment, since inner cities generally have a higher concentration of key daily destinations, including workplaces, retail and grocery stores, cultural facilities, and public authorities.

Various urban structural variables were initially constructed for the analysis. The GIS-based accessibility tool described in Section 3.2 was used to measure travel times and distance (via the road network) from the respondents' residences to key daily destinations taken from the GILDA database. Most variables used in the analyses presented here would be considered more regional on the neighborhood-region continuum. Neighborhood-scale variables such as population density within the residential area were much less correlated with the dependent variables. Such variables could be expected to be more relevant when, for example, examining only non-work travel and how neighborhood design can encourage walking/biking instead of car driving when performing service errands or leisure activities. A list and further description of the urban form variables used in the present analyses here appear in Table 2.

Table 2: Description of urban form variables

\begin{tabular}{|l|l|}
\hline & \\
\hline Regional & \\
\hline City center, car & Travel time by car in minutes via the road network to Gothenburg central station \\
\hline City center, PT & Travel time by PT in minutes via the road network to Gothenburg central station \\
\hline City center, distance & Distance via the road network in meters to Gothenburg central station \\
\hline Population, $5 \mathrm{~km}$ & Number of people living within $5 \mathrm{~km}$ via the road network \\
\hline Jobs, $5 \mathrm{~km}$ & Number of jobs within $5 \mathrm{~km}$ via the road network \\
\hline JWR, $5 \mathrm{~km}$ & $\begin{array}{l}\text { The number of job opportunities relative to the number of gainfully employed living } \\
\text { within } 5 \mathrm{~km} \text { via the road network }\end{array}$ \\
\hline Local & \\
\hline Local center, car & Travel time by car in minutes via the road network to the closest local center \\
\hline Local center, PT & Travel time by PT in minutes via the road network to the closest local center \\
\hline $\begin{array}{l}\text { Local center, } \\
\text { distance }\end{array}$ & Distance via the road network in meters to the closest local center \\
\hline Groceries, car & Travel time by car in minutes via the road network to the closest grocery store \\
\hline Groceries, PT & Travel time by PT in minutes via the road network to the closest grocery store \\
\hline Groceries, distance & Distance via the road network in meters to the closest grocery store \\
\hline Population, $1 \mathrm{~km}$ & Number of people living within 1 km via the road network \\
\hline Jobs, $1 \mathrm{~km}$ & Number of jobs within 1 km via the road network \\
\hline JWR, $1 \mathrm{~km}$ & $\begin{array}{l}\text { The number of job opportunities relative to the number of gainfully employed living } \\
\text { within } 1 \mathrm{~km} \text { via the road network }\end{array}$ \\
\hline
\end{tabular}

${ }^{a}$ A local center is defined as the location of the train station in a suburban town with more than 10,000 inhabitants (i.e., Kungälv, Lerum, Mölndal, Mölnlycke, Lindome, and Kungsbacka, as shown in Figure 1).

Furthermore, bivariate Pearson correlations were fitted to evaluate how the urban form variables covary (see Appendix A). As expected, most of the variables were significantly correlated with each other. 
Note that if the urban form variables are roughly divided into more regional (e.g., distance to city center) and more local (e.g., distance to closest grocery store and jobs within 1 kilometer) variables, they are generally most correlated with other variables on a similar scale. The models were later built step-wise with the help of the correlation matrix to achieve the best fits as described in the following section. It is important to note that the precise aim is not to evaluate the exact characteristics of the built environment that influence travel but rather to determine to what extent overall daily travel is related to urban structure.

\subsection{Step-wise analysis}

The aim of the paper was attained using bivariate Pearson correlation and ordinary least square (OLS) regression models. The analysis was carried out step-wise. First, simple descriptive Pearson correlations of the urban form and the dependent variables were determined. These results were used to select variables for the regression analysis by evaluating which of the urban form variables were most correlated with the dependent variables for the different groups. Second, base models including only the socioeconomic and demographic variables were fitted. These models were used to control for possible individual interactions and are only briefly elaborated on in the ensuing analysis. Finally, urban form variables were added to evaluate their contribution to explaining the variation in travel-behavior dependent variables. Observation of how $\mathrm{R}^{2}$ values change and F-tests are used to measure the improvement of the model due to adding the variables. Two sets of models are presented for each dependent variable. In the first set, different models were fitted for those who did and did not report teleworking regularly. In the second set of models, only those who reported teleworking regularly are included. The separate groups were then analyzed based on whether or not they teleworked on the survey day.

\section{$4 \quad$ Results}

\subsection{Comparing regular teleworkers with non-teleworkers}

\subsubsection{Bivariate correlation analysis}

The results of the correlations comparing the non-teleworking group with everyone who reported teleworking regularly are presented in Table 3. A preliminary observation is that most of the urban structural variables are significantly correlated with the distance traveled on the survey day. These correlations suggest, as expected, that the closer workers live to the city center, jobs, population, grocery stores, etc., the less distance they can be expected to travel. The more regional urban structural variables (i.e., location of the residence relative to the center of Gothenburg and the number of jobs or population within 5 kilometers) display the strongest correlations overall. The bivariate correlations also suggest that there are differences in how the urban form relates to daily travel distance between those who telework regularly and those who do not. Of the urban structure variables, a majority displays stronger correlations with travel distance for those who do not regularly telework than for those who do. The distance and travel time to the closest local center from the home location are not significantly related to how far the regular teleworkers travel on workdays. 
Table 3: Pearson correlations comparing regular teleworkers with non-teleworkers

\begin{tabular}{|l|c|c|c|c|}
\hline & \multicolumn{2}{|c|}{ Travel distance $(\mathbf{L N ~ k m )}$} & \multicolumn{2}{c|}{ Travel time (LN min) } \\
\hline & $\begin{array}{c}\text { Non-teleworker } \\
(\boldsymbol{n}=\mathbf{1 4 5 3})\end{array}$ & $\begin{array}{c}\text { Teleworker } \\
(\boldsymbol{n}=\mathbf{4 5 3})\end{array}$ & $\begin{array}{c}\text { Non-teleworker } \\
(\boldsymbol{n}=\mathbf{1 5 9 2})\end{array}$ & $\begin{array}{c}\text { Teleworker } \\
(\boldsymbol{n}=\mathbf{4 8 4})\end{array}$ \\
\hline Regional & $0.209^{* *}$ & $0.203^{* *}$ & $0.082^{* *}$ & $0.107^{*}$ \\
\hline City center, car & $0.213^{* *}$ & $0.223^{* *}$ & $0.089^{* *}$ & $0.111^{*}$ \\
\hline City center, PT & $0.235^{* *}$ & $0.222^{* *}$ & $0.064^{*}$ & 0.067 \\
\hline $\begin{array}{l}\text { City center, dis- } \\
\text { tance }\end{array}$ & $-0.225^{* *}$ & $-0.202^{* *}$ & $-0.086^{* *}$ & -0.069 \\
\hline Population, 5 km & $-0.232^{* *}$ & $-0.205^{* *}$ & $-0.083^{* *}$ & -0.062 \\
\hline Jobs, 5 km & $-0.169^{* *}$ & $-0.172^{* *}$ & -0.041 & -0.042 \\
\hline JWR, 5 km & & & & $0.100^{*}$ \\
\hline Local & $0.133^{* *}$ & 0.084 & $0.078^{* *}$ & $0.100^{*}$ \\
\hline Local center, car & $0.100^{* *}$ & 0.084 & $0.058^{*}$ & 0.078 \\
\hline Local center, PT & $0.156^{* *}$ & 0.090 & $0.065^{* *}$ & 0.039 \\
\hline $\begin{array}{l}\text { Local center, } \\
\text { distance }\end{array}$ & $0.180^{* *}$ & $0.155^{* *}$ & $0.087^{* *}$ & 0.005 \\
\hline Groceries, car & $0.197^{* *}$ & $0.129^{* *}$ & $0.084^{* *}$ & 0.026 \\
\hline Groceries, PT & $0.211^{* *}$ & $0.160^{* *}$ & $0.084^{* *}$ & -0.039 \\
\hline Groceries, distance & $-0.193^{* *}$ & $-0.150^{* *}$ & -0.038 & -0.071 \\
\hline Population, 1 km & $-0.220^{* *}$ & $-0.190^{* *}$ & $-0.072^{* *}$ & -0.047 \\
\hline Jobs, 1 km & $-0.086^{* *}$ & $-0.100^{*}$ & -048 \\
\hline JWR, 1 km & & & & \\
\hline
\end{tabular}

${ }^{*} p<0.05^{* *} p<0.01$

If travel behavior is operationalized as daily time spent traveling, the magnitude of the correlations are generally smaller and do not exhibit the same differences between the groups as for distance. Most of the urban form variables are significantly correlated $(p<0.05)$ with travel time for the non-teleworkers. However, how much time a teleworker spends traveling on workdays is related significantly only to the time it takes to travel by car or PT to the city center or closest local center. Again, the more regional variables tend to display the stronger correlations, although the pattern is not as clear as for distance. The location of the residence relative to the city center remains important in the case of travel time as well. As expected, the distance via the road network is less important when predicting daily travel time than is the travel time by PT or car between the home and city center. Furthermore, and as expected, the farther away workers live from the city center, jobs, grocery stores, etc., the more time they can be expected to spend traveling on workdays.

In conclusion, the correlation analysis results suggest that there are differences in how the urban structure relates to daily travel depending on whether or not one teleworks regularly. These correlations indicate that urban structure is less important for those teleworking regularly when operationalizing travel behavior as daily distance or time. These indications are further explored using regression models elaborated on in the following section.

\subsubsection{Regression analysis}

Several models were initially fitted based on the problems of correlation between the variables describing urban structure discussed earlier and on the outcomes of the bivariate correlations. The models using travel distance as the dependent variable are discussed first (see Table 4). As suspected from the correlation matrix (Appendix A), the best model fits were achieved when adding both one regional and one 
local variable; there were no setups in which adding a third urban form variable improved the fit. The models presented here include the distance from home (via the road network) to city center and to the closest grocery store; these two variables together achieved the best overall fit. The results of adding only the other variables (alone or paired), however, were largely the same in terms of the difference in explanatory value between the groups. The largest differences were found for certain urban form variables (e.g., distance/travel time to a local center), which did not contribute at all when fitting the model for regular teleworkers but were important in explaining variation in non-teleworkers' daily travel distance. Furthermore, the variables for individual characteristics together explain more of the variation in daily travel distance than do the urban structure variables (i.e., $\mathrm{R}^{2}$ values before and after adding the urban form variables). This confirms the importance of controlling for individual characteristics when studying urban structure-travel interactions. Another expected observation is that car access is clearly the most important variable. Access to a car generally results in considerably greater daily travel distances, regardless of whether a person teleworks regularly or whether the urban form variables are controlled for.

Furthermore, the results of the regression analysis suggest weaker urban structure-travel relationships for regular teleworkers than non-teleworkers. Adding the urban form variables contributes considerably more to explaining the variation in distance traveled on the survey day for non-teleworkers: The $\mathrm{R}^{2}$ increased by 0.050 as a result of adding the urban form variables for this group but by only 0.029 for those who telework regularly. F-tests, however, indicate that the urban form variables contribute significantly to both models, though the F-statistic is considerably lower for the teleworkers $(6.789, p<$ 0.01 ) than the non-teleworkers (36.931, $p<0.001$ ). Not surprisingly, residential location relative to the city center of Gothenburg is significant for both groups. In general, whether or not a person teleworks regularly, living closer to the city center will reduce the daily travel distance. The magnitude of this effect is similar for both groups $(0.250$ versus 0.254$)$. The distance to the closest grocery store is significant only for non-teleworkers when simultaneously controlling for the distance between home and city center. However, when omitting this variable, the nearest grocery store variable becomes significant even for those who telework regularly. But once again, the significance levels of the parameter estimates, the change in $\mathrm{R}^{2}$, and the F-tests all indicate weaker urban structure-travel relationships for regular teleworkers than non-teleworkers. 


\begin{tabular}{|c|c|c|c|c|c|c|c|c|c|c|c|c|c|c|c|c|c|c|c|c|c|c|c|c|c|}
\hline \multirow{4}{*}{\multicolumn{2}{|c|}{ 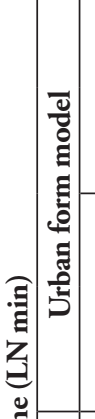 }} & \multirow{2}{*}{ 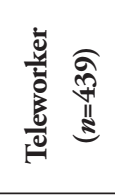 } &. & & 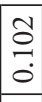 & $\stackrel{2}{\overrightarrow{0}}$ & $\begin{array}{l}\hat{\infty} \\
\stackrel{0}{0} \\
\end{array}$ & $\begin{array}{l}\hat{0} \\
0 \\
0 \\
\end{array}$ & $\begin{array}{l}\infty \\
\infty \\
\vdots \\
0 \\
\end{array}$ & $\begin{array}{l}m \\
\vec{t} \\
0\end{array}$ & 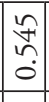 & 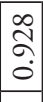 & 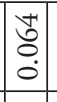 & \begin{tabular}{r|r}
0 \\
$\infty$ \\
$\infty$ \\
0 \\
\end{tabular} & 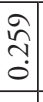 & & & ळे & $\begin{array}{l}8 \\
\vdots \\
\vdots \\
\end{array}$ & & \multirow{2}{*}{$\left|\begin{array}{cc}0 & \stackrel{0}{0} \\
0 & \overline{0} \\
0 & \overline{ \pm}\end{array}\right|$} & \multirow{2}{*}{\begin{tabular}{c}
$m$ \\
$\vdots$ \\
\hdashline
\end{tabular}} & \multirow{2}{*}{$\begin{array}{l}\hat{\sigma} \\
8 \\
0 \\
\dot{0}\end{array}$} & \multirow{2}{*}{\multicolumn{2}{|c|}{ 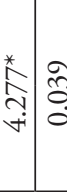 }} \\
\hline & & & $\infty$ & & 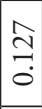 & $\widetilde{\sigma}$ & $\begin{array}{l}n \\
\tilde{\sigma} \\
\dot{0}\end{array}$ & $\begin{array}{l}\hat{A} \\
0 \\
0\end{array}$ & $\overrightarrow{8}$ & $\begin{array}{l}\overrightarrow{\hat{\sigma}} \\
\dot{\varphi}\end{array}$ & $\begin{array}{l}0 \\
\vdots \\
\vdots \\
0\end{array}$ & 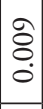 & 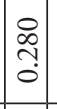 & $\begin{array}{l}0 \\
\vdots \\
\vdots \\
i\end{array}$ & $\begin{array}{l}\infty \\
\stackrel{0}{0} \\
0 \\
0\end{array}$ & & & $\stackrel{*}{\stackrel{*}{n}}$ & $\begin{array}{l}\widehat{\widehat{\sigma}} \\
\text { ๙े}\end{array}$ & & & & & & \\
\hline & & \multirow{2}{*}{ 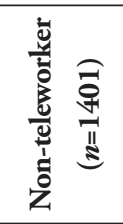 } &.$\frac{60}{5}$ & $\begin{array}{l}0 \\
\vdots \\
0\end{array}$ & ठิ & $\stackrel{8}{\circ}$ & $\begin{array}{l}\text { त్రి } \\
0 \\
\end{array}$ & $\begin{array}{l}\vec{Z} \\
0 \\
0 \\
0\end{array}$ & $\begin{array}{l}n \\
0 \\
0 \\
0 \\
\end{array}$ & $\begin{array}{l}0 \\
\infty \\
+ \\
0 \\
\end{array}$ & 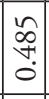 & $\begin{array}{l}2 \\
\infty \\
0 \\
0 \\
\end{array}$ & $\begin{array}{l}\infty \\
\grave{\delta} \\
\end{array}$ & $\begin{array}{l}n \\
\hat{n} \\
0\end{array}$ & $\begin{array}{l}2 \\
\vdots \\
0\end{array}$ & & & & $\begin{array}{l}\vdots \\
\vdots \\
\vdots \\
\end{array}$ & ○ & \multirow{2}{*}{ 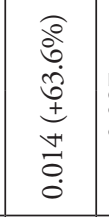 } & \multirow{2}{*}{$\begin{array}{c}\widehat{c} \\
0 \\
0 \\
0\end{array}$} & \multirow{2}{*}{\begin{tabular}{|l|}
$*$ \\
$\vdots$ \\
0
\end{tabular}} & \multirow{2}{*}{\multicolumn{2}{|c|}{ 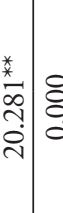 }} \\
\hline & & & $\infty$ & & 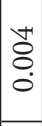 & & $\begin{array}{l}0 \\
0 \\
0 \\
0 \\
i\end{array}$ & $\begin{array}{l}m \\
\vdots \\
0 \\
0\end{array}$ & $\begin{array}{l}\infty \\
0 \\
\vdots \\
0\end{array}$ & ชิ & $\begin{array}{l}\infty \\
\tilde{0} \\
\vdots \\
i\end{array}$ & 艿 & $\begin{array}{l}8 \\
\vdots \\
\vdots\end{array}$ & 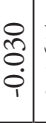 & 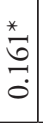 & & & $\begin{array}{l}\text { * } \\
\stackrel{*}{0} \\
\stackrel{0}{0}\end{array}$ & ले. & ○ी & & & & & \\
\hline | & \multirow{4}{*}{ 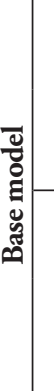 } & \multirow{2}{*}{ 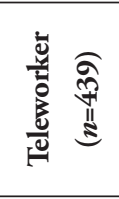 } & .60 & mo & $\begin{array}{l}\infty \\
\infty \\
0 \\
0 \\
\end{array}$ & & $\begin{array}{l}\tilde{\hat{n}} \\
\hat{0}\end{array}$ & 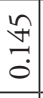 & $\begin{array}{l}\infty \\
0 \\
\infty \\
0 \\
0\end{array}$ & $\begin{array}{l}m \\
m \\
0\end{array}$ & $\begin{array}{l}\mathfrak{d} \\
\text { o. } \\
\end{array}$ & $\begin{array}{l}\infty \\
\infty \\
2 \\
0 \\
\end{array}$ & $\begin{array}{l}+4 \\
\stackrel{1}{0} \\
0 \\
\end{array}$ & $\begin{array}{c}1 \\
\text { on } \\
0 \\
0\end{array}$ & $\begin{array}{l}2 \\
\overrightarrow{0}\end{array}$ & & & & $\begin{array}{l}0 \\
\vdots \\
\vdots \\
\end{array}$ & \multirow{2}{*}{ م̂ } & & \multirow{2}{*}{$\begin{array}{l}\bullet \\
\vdots \\
\vdots\end{array}$} & & & \\
\hline & & & $\infty$ & 8 & $\stackrel{m}{0}$ & $\bar{\sigma}$ & $\begin{array}{l}\infty \\
0 \\
0 \\
0\end{array}$ & $\begin{array}{l}8 \\
0 \\
0\end{array}$ & $\begin{array}{l}n \\
0 \\
0 \\
0\end{array}$ & $\begin{array}{l}\infty \\
0 \\
0 \\
0 \\
\end{array}$ & $\begin{array}{l}\hat{0} \\
0 \\
0\end{array}$ & $\begin{array}{l}2 \\
0 \\
\dot{\varphi} \\
\end{array}$ & 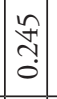 & $\begin{array}{c}\vec{a} \\
\vdots \\
\vdots \\
\end{array}$ & $\begin{array}{l}\Omega \\
\vdots \\
0 \\
\end{array}$ & & & & 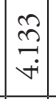 & & & & & & \\
\hline & & 崩 &.$\frac{.00}{5}$ & $\tilde{\varepsilon}$ & $\begin{array}{l}\stackrel{+}{\hat{N}} \\
\text { o } \\
\end{array}$ & है & $\begin{array}{l}m \\
\infty \\
0 \\
0\end{array}$ & $\begin{array}{l}\swarrow \\
\vdots\end{array}$ & 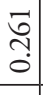 & 䒕 & \begin{tabular}{|l|}
$\vec{m}$ \\
0
\end{tabular} & 茪 & $\begin{array}{l}\infty \\
\vdots \\
\vdots \\
\vdots\end{array}$ & $\begin{array}{l}\bar{n} \\
\hat{0} \\
\end{array}$ & $\begin{array}{l}\widetilde{a} \\
0 \\
0 \\
\end{array}$ & & & & $\begin{array}{l}\vdots \\
\vdots \\
\vdots\end{array}$ & \multirow{2}{*}{ ลี } & & \multirow{2}{*}{$\begin{array}{l}m \\
\vdots \\
0 \\
0\end{array}$} & & & \\
\hline & & 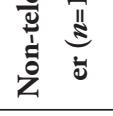 & $\infty$ & & $\overrightarrow{0}$ & * & $\begin{array}{l}\forall \\
\\
0 \\
\\
\end{array}$ & $\overrightarrow{8}$ & $\begin{array}{l}\vec{n} \\
\vdots \\
0\end{array}$ & ஜे & $\begin{array}{c}0 \\
0 \\
0 \\
\vdots \\
1\end{array}$ & $\mid \begin{array}{l}\text { ô } \\
0 \\
\dot{i}\end{array}$ & $\begin{array}{l}0 \\
\vdots \\
0 \\
\vdots \\
\end{array}$ & \begin{tabular}{l|}
0 \\
$\vdots$ \\
$\vdots$ \\
\end{tabular} & 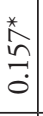 & & & & $\begin{array}{l}\grave{\vdots} \\
\grave{r}\end{array}$ & & & & & & \\
\hline \multirow{4}{*}{\multicolumn{2}{|c|}{ 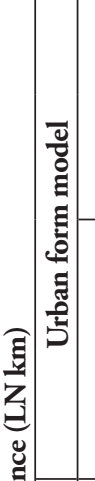 }} & \multirow{2}{*}{ 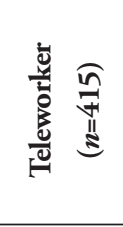 } & $\frac{60}{\infty}$ & $\approx$ & $\hat{\kappa}$ & & 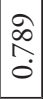 & $\begin{array}{l}\stackrel{m}{\forall} \\
0\end{array}$ & 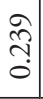 & $\begin{array}{l}\widehat{\hat{\sigma}} \\
0 \\
0\end{array}$ & $\mid \begin{array}{l}0 \\
0 \\
0 \\
0 \\
\end{array}$ & $\tilde{\tilde{\sigma}}$ & $\left|\begin{array}{l}\infty \\
0 \\
0 \\
0\end{array}\right|$ & 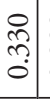 & $\begin{array}{l}\tilde{\Xi} \\
\text { லे }\end{array}$ & & $\frac{a}{a}$ & & $\begin{array}{l}0 \\
\vdots \\
0\end{array}$ & \multirow{2}{*}{\multicolumn{2}{|c|}{ 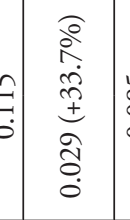 }} & & & * & \\
\hline & & & $\infty$ & 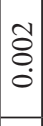 & 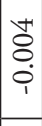 & 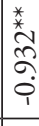 & $\mid \begin{array}{l}0 \\
0 \\
0 \\
0\end{array}$ & $\begin{array}{c}\stackrel{\infty}{+} \\
\stackrel{0}{0}\end{array}$ & $\begin{array}{l}\infty \\
\stackrel{0}{0} \\
0 \\
0\end{array}$ & $\begin{array}{l}\stackrel{a}{े} \\
\dot{\varphi}\end{array}$ & \begin{tabular}{l}
\multirow{1}{*}{} \\
bे \\
$\dot{0}$
\end{tabular} & 总 & 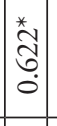 & $\begin{array}{c}\infty \\
\infty \\
\vdots \\
i \\
\end{array}$ & \begin{tabular}{l}
\multirow{2}{*}{} \\
ô. \\
0
\end{tabular} & & $\stackrel{\tilde{q}}{\mathbb{c}}$ & & $\begin{array}{l}0 \\
\infty \\
i \\
i\end{array}$ & & & & & 离. & c \\
\hline & & 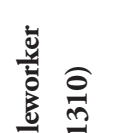 &.$\frac{.00}{6}$ & $\begin{array}{l}0 \\
\vdots \\
\vdots\end{array}$ & 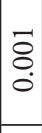 & @ & $\begin{array}{l}\hat{n} \\
\hat{o}\end{array}$ & 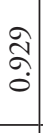 & 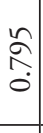 & $\hat{n}$ & $\left|\begin{array}{c}\tilde{D} \\
0 \\
0 \\
0\end{array}\right|$ & 恿 & $\begin{array}{c}-1 \\
- \\
0\end{array}$ & | & $\begin{array}{l}\text { Зీ} \\
0 \\
0\end{array}$ & & ఏ & & $\begin{array}{l}8 \\
\vdots \\
0 \\
\end{array}$ & กี & 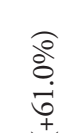 & $\approx$ & & $\frac{v_{0}}{\sigma}$ & \\
\hline & & 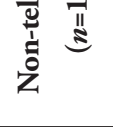 & $\infty$ & $\stackrel{*}{\stackrel{*}{*}}$ & 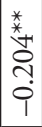 & مُ & 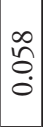 & $\begin{array}{l}\hat{o} \\
\vdots \\
\dot{i}\end{array}$ & $\begin{array}{l}\infty \\
0 \\
0 \\
\vdots \\
\end{array}$ & $\begin{array}{l}0 \\
0 \\
0 \\
\dot{1}\end{array}$ & $\mid \begin{array}{c}\infty \\
0 \\
0 \\
\dot{i} \\
\end{array}$ & 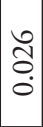 & 离 & $\begin{array}{l}0 \\
0 \\
\vdots \\
\vdots\end{array}$ & $\begin{array}{l}\vec{n} \\
0 \\
0\end{array}$ & & 烍 & & 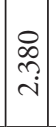 & $\overrightarrow{0}$ & 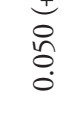 & & 0 & ڤેें| & \\
\hline | & & $\stackrel{\frac{5}{5}}{\frac{n}{2}}$ & . & $\stackrel{f}{f}$ & $\mid \begin{array}{l}\infty \\
\sim \\
\infty \\
0 \\
0\end{array}$ & & 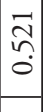 & $\begin{array}{l}n \\
\hat{\alpha} \\
\delta\end{array}$ & $\begin{array}{l}n \\
0 \\
0 \\
0\end{array}$ & \begin{tabular}{l} 
âे. \\
\multirow{0}{0}{}
\end{tabular} & ڤ్ & $\hat{\sigma}$ & $\left|\begin{array}{l}\infty \\
0 \\
0 \\
0\end{array}\right|$ & 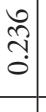 & $\begin{array}{l}n \\
0 \\
0 \\
0 \\
0\end{array}$ & & & & $\begin{array}{l}\vdots \\
\vdots \\
\vdots\end{array}$ & $\infty$ & & $\approx$ & & & \\
\hline$F$ & $\begin{array}{l}\overline{\widetilde{z}} \\
\bar{g} \\
\underline{g}\end{array}$ & $\frac{\vec{E}}{\tilde{E}}=$ & $\infty$ & 8 & $\begin{array}{l}\tilde{0} \\
0 \\
0\end{array}$ & & 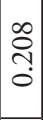 & $\begin{array}{l}\infty \\
\stackrel{0}{0} \\
0\end{array}$ & 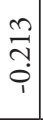 & $\begin{array}{l}\infty \\
0 \\
0 \\
0\end{array}$ & $\mid$ & 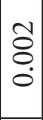 & $\left|\begin{array}{l}\infty \\
\multirow{\sigma}{0}{} \\
0\end{array}\right|$ & $\begin{array}{l}\text { ה̃ } \\
\text { ș } \\
\vdots\end{array}$ & $\begin{array}{l}\hat{\delta} \\
\dot{0}\end{array}$ & & & & 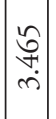 & : & & 0 & & & \\
\hline & صू & 离 & .60 & & 令 & & 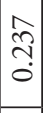 & 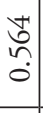 & $\begin{array}{l}\stackrel{0}{n} \\
0 \\
0\end{array}$ & ڤે. & $\mid \begin{array}{l}0 \\
\hat{0} \\
0 \\
0\end{array}$ & 点 & ڤે & \begin{tabular}{c}
$\infty$ \\
\multirow{+}{0}{} \\
0
\end{tabular} & 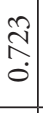 & & & & $\begin{array}{l}8 \\
\vdots \\
\vdots\end{array}$ & & & & & & \\
\hline & & 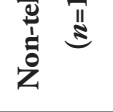 & $\infty$ & & $\begin{array}{l}\text { 类 } \\
\text { o } \\
? \\
0 \\
\end{array}$ & & $\begin{array}{l} \pm \\
- \\
0 \\
0\end{array}$ & $\begin{array}{l}\text { के } \\
\text { } \\
\dot{i}\end{array}$ & $\begin{array}{l}+1 \\
0 \\
\vdots \\
\vdots\end{array}$ & $\begin{array}{l}+ \\
0 \\
0 \\
\dot{\varphi}\end{array}$ & $\begin{array}{l}0 \\
0 \\
0 \\
0 \\
0\end{array}$ & 合 & $\left|\begin{array}{l}n \\
\vdots \\
0 \\
0\end{array}\right|$ & 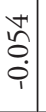 & 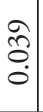 & & & & $\begin{array}{l}\stackrel{n}{\check{n}} \\
\dot{m}\end{array}$ & 0 & & & & & \\
\hline
\end{tabular}


With respect to travel time, we first fitted several models, altering the setup of the urban form variables. Only two of the urban form variables, however, contributed significantly to explaining the daily travel time of those who telework regularly, i.e., travel time by car or PT to the city center. The models with travel time as the dependent variable (also presented in Table 4), therefore, include only travel time by PT between home and city center. ${ }^{4}$ Again, the individual variables are only briefly discussed before considering the urban form variables in more detail. Access to a car-unlike when modeling travel distance-is significant only for those who do not regularly telework. As in the travel distance models, the variables for individual characteristics explain more of the variation in travel time than do the urban form variables.

Returning to the main question asked here, concerning whether telework weakens the relationship between urban form and travel behavior, similar indications can be found when operationalizing travel behavior as travel time but not as strong as in the case of travel distance. A person-whether or not a regular teleworker — can be expected to travel for a longer time on a workday the longer it takes that person to reach the city center from home. This effect is statistically stronger for the group that does not telework: The $\mathrm{R}^{2}$ increased by 31.3 percent $(\mathrm{F}, p<0.05)$ as a result of adding the urban form variables for regular teleworkers versus by 63.6 percent $(\mathrm{F}, p<0.001)$ for those who do not. However, the differences in raw changes of $R^{2}(0.014$ versus 0.010$)$ and effect sizes $(0.166$ versus 0.151$)$ are small. The $R^{2}$ values are also low, and $97-98$ percent of the variance in travel time is left unexplained.

\subsection{Comparing regular teleworkers based on whether or not they teleworked on the survey day}

\subsubsection{Bivariate correlation analysis}

To more directly analyze whether telework affects the relationships between urban structure and travel behavior, regular teleworkers are compared based on whether or not they teleworked on the survey day. The results of the bivariate correlation analysis are presented in Table 5. In the case of travel distance, the outcome of the correlations is similar to when one distinguishes between regular teleworkers and non-teleworkers. Living closer to the city center, a grocery store, jobs, etc., makes it more likely one will travel a shorter distance on workdays. The correlation results also suggest that this relationship is weaker on the days that a person teleworks. Most of the urban form variables are significantly correlated with the travel distance of those not teleworking on the survey day. Meanwhile, several variables do not display significant correlations for those teleworking on the survey day and the correlation coefficients are mostly of smaller magnitude.

These differences are more obvious when we instead analyze the relationship between the spatial variables and time spent traveling on the survey day (see Table 5). None of the urban form variables is significantly correlated with travel time for those teleworking on the survey day. Regular teleworkers, however, can be expected to travel for less time on non-teleworking workdays if they live closer to a local center or the city center and the correlations are generally stronger.

\footnotetext{
${ }^{4}$ Travel time by PT was slightly better at explaining the daily time spent traveling.
} 
Table 5: Pearson correlations comparing regular teleworkers based on whether or not they teleworked on the survey day

\begin{tabular}{|c|c|c|c|c|}
\hline & \multicolumn{2}{|c|}{ Travel distance $(\mathbf{L N ~ k m )}$} & \multicolumn{2}{c|}{ Travel time (LN min) } \\
\hline & No telework $(\boldsymbol{n}=\mathbf{3 0 0})$ & Telework $(\boldsymbol{n}=\mathbf{1 5 1})$ & No telework $(\boldsymbol{n}=317)$ & Telework $(\boldsymbol{n}=\mathbf{1 6 5})$ \\
\hline Regional & & & & $0.127^{*}$ \\
\hline City center, car & $0.210^{* *}$ & $0.201^{*}$ & $0.125^{*}$ & 0.080 \\
\hline City center, PT & $0.245^{* *}$ & $0.199^{*}$ & 0.071 & 0.096 \\
\hline City center, distance & $0.210^{* *}$ & $0.247^{* *}$ & -0.077 & -0.060 \\
\hline Population, 5 km & $-0.205^{* *}$ & $-0.202^{*}$ & -0.077 & -0.036 \\
\hline Jobs, $5 \mathrm{~km}$ & $-0.211^{* *}$ & $-0.199^{*}$ & -0.068 & 0.003 \\
\hline JWR, 5 km & $-0.178^{* *}$ & -0.156 & & 0.020 \\
\hline Local & & & $0.158^{* *}$ & 0.057 \\
\hline Local center, car & $0.134^{*}$ & 0.007 & $0.132^{*}$ & 0.011 \\
\hline Local center, PT & $0.116^{*}$ & 0.032 & $0.123^{*}$ & 0.011 \\
\hline Local center, distance & $0.132^{*}$ & 0.022 & 0.061 & -0.003 \\
\hline Groceries, car & $0.172^{* *}$ & 0.140 & 0.009 & 0.013 \\
\hline Groceries, PT & 0.113 & $0.161^{*}$ & 0.030 & -0.015 \\
\hline Groceries, distance & $0.152^{* *}$ & $0.174^{*}$ & -0.048 & -0.010 \\
\hline Population, $1 \mathrm{~km}$ & $-0.132^{*}$ & $-0.173^{*}$ & -0.105 & -0.118 \\
\hline Jobs, 1 km & $-0.202^{* *}$ & $-0.166^{*}$ & -0.045 & \\
\hline JWR, 1 km & -0.108 & -0.154 & & \\
\hline
\end{tabular}

$* p<0.05^{* *} p<0.01$

\subsubsection{Regression analysis}

Table 6 presents the regression models that analyze only the regular teleworkers but compare them according to whether or not they teleworked on the survey day. Overall, the results of these models further confirm the outcomes discussed above. In the case of travel distance, the relative increase in $\mathrm{R}^{2}$ is considerably smaller for the group that teleworked on the survey day, while none of the urban form variables is significant. Meanwhile, as in the model including all regular teleworkers, distance to the city center is significant for those who did not telework on the survey day. Furthermore, the F-tests indicate that the urban variables are only weakly related to distance traveled on workdays when teleworking is performed, the F-statistic of 2.108 not being significant at the 5 percent level. There is, however, a very low probability $(p<0.01)$ that the urban form variables do not explain any variation in travel distance among those not teleworking on the survey day. These differences also hold when altering the urban form variables. All variables contribute more to explaining the travel distance of those not teleworking on the survey day. Very few setups of the urban form variables result in any significant contribution at the 5 percent significance level when modeling the travel distance of those teleworking on the survey day, the few exceptions occurring with the addition of only one of the city center variables. Once again, however, the effect is more strongly related to travel distance on non-teleworking workdays. Furthermore, the variables for individual characteristics again explain more of the variation in travel distance than do the urban form variables. As expected, car access is an important determinant of how far a worker-teleworking or not-travels on workdays.

If the dependent variable is changed to travel time, the differences between the groups become more obvious. The urban form variable (i.e., travel time by PT between home and city center) is not significant when fitting the model for those teleworking on the survey day. Regular teleworkers, however, can be expected to travel for a longer time on non-teleworking workdays if they live farther from the city center. The model statistics clearly confirm these results. The F-test for model improvement when adding the urban form variable is not significant and there is almost no change in $\mathrm{R}^{2}$ for those 
teleworking on the survey day. The F-test, however, confirms that the urban form variable contributes significantly $(p<0.01)$ to the model fitted for those not teleworking on the survey day. In other words, where a worker lives relative to various urban structure features has very little to do with how much time that worker spends traveling on teleworking days. The model outcome instead suggests that education is a determinant of daily travel time when teleworking, with less educated workers traveling for longer times. These results, however, only apply to those teleworking on the survey day; none of the variables for individual characteristics is significant for the other group. 


\begin{tabular}{|c|c|c|c|c|c|c|c|c|c|c|c|c|c|c|c|c|c|c|c|c|c|c|c|c|}
\hline & \begin{tabular}{|l}
$\bar{g}$ \\
$\bar{z}$ \\
$\vdots$ \\
$g$ \\
$g$
\end{tabular} & 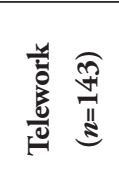 &.$\frac{60}{\bar{\omega}}$ & 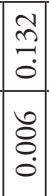 & 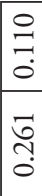 & 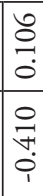 & 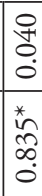 & 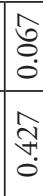 & 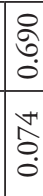 & 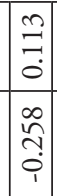 & 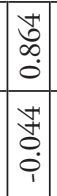 & 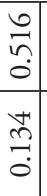 & 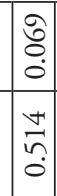 & 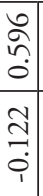 & 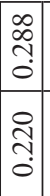 & & & $\begin{array}{l}n \\
\hat{n} \\
0 \\
\overrightarrow{0} \\
0 \\
0 \\
0\end{array}$ & 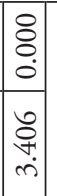 & $\vec{a}$ & $\begin{array}{l}0 \\
0 \\
\vdots \\
\vdots \\
\vdots \\
\vdots \\
\vdots \\
\vdots\end{array}$ & 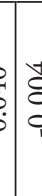 & $\frac{0}{m}$ & ڤn \\
\hline & 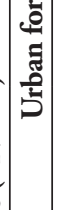 & 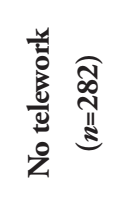 &.$\frac{20}{\omega}$ & 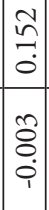 & 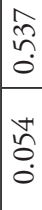 & 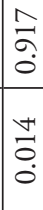 & 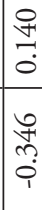 & 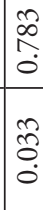 & 衣 & 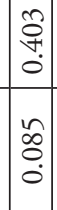 & 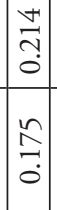 & 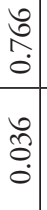 & 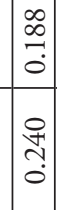 & $\begin{array}{l}0 \\
n \\
0 \\
0 \\
\overrightarrow{0} \\
0 \\
\vdots \\
1\end{array}$ & 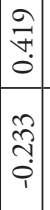 & & & 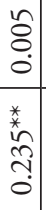 & 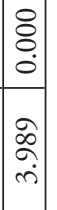 & $\begin{array}{l}\hat{\hat{o}} \\
\dot{0}\end{array}$ & & & $\mid$\begin{tabular}{l}
$*$ \\
$\stackrel{*}{*}$ \\
\multirow{3}{*}{} \\
$\infty$ \\
$\infty$
\end{tabular} & . \\
\hline & $\mid \bar{v}$ & 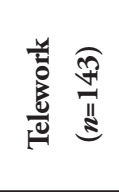 & .00 & 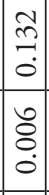 & 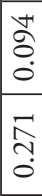 & 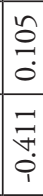 & 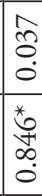 & 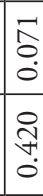 & \begin{tabular}{l}
$\infty$ \\
\hdashline \\
0 \\
0
\end{tabular} & 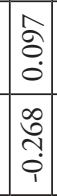 & 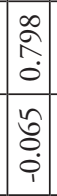 & 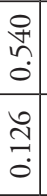 & \begin{tabular}{|l|} 
\\
0 \\
0 \\
0 \\
0 \\
0 \\
0 \\
0 \\
\end{tabular} & 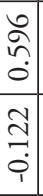 & 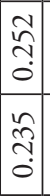 & & ' & I & 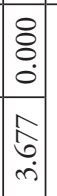 & $\Omega$ & ปt & & & \\
\hline & $\left|\begin{array}{|c}\mid \\
\tilde{u} \\
\tilde{n}\end{array}\right|$ & 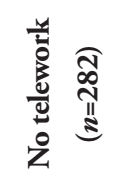 &.$\frac{20}{\bar{\omega}}$ & 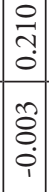 & 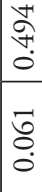 & 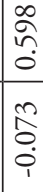 & 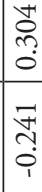 & 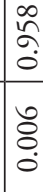 & 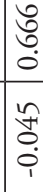 & $\begin{array}{l}0 \\
\tilde{n} \\
0 \\
0 \\
\vec{b} \\
\vdots \\
0\end{array}$ & 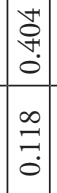 & $\begin{array}{l}+ \\
\infty \\
0 \\
0 \\
0 \\
\infty \\
0 \\
0 \\
0\end{array}$ & 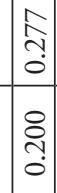 & 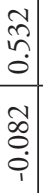 & 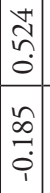 & & ' & I & 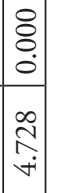 & $\stackrel{0}{\circ}$ & 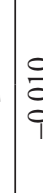 & & & \\
\hline & $\begin{array}{c}\overline{\mathrm{g}} \\
\bar{g} \\
\mathrm{~g} \\
\mathrm{~g}\end{array}$ & 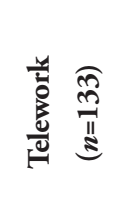 &.$\frac{.00}{\omega}$ & ठे & 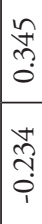 & 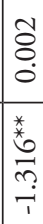 & 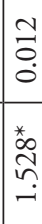 & 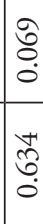 & 苍 & 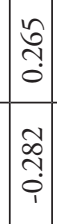 & 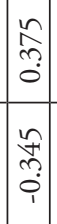 & 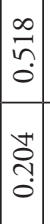 & 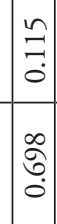 & 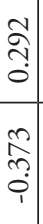 & $\mid \begin{array}{l}\infty \\
0 \\
0 \\
i \\
1\end{array}$ & 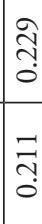 & \begin{tabular}{|l|}
0 \\
0 \\
0 \\
0 \\
0 \\
0 \\
0 \\
0 \\
0
\end{tabular} & ' & 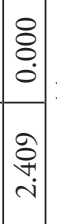 & 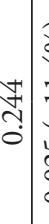 & & & 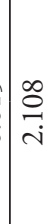 & $\stackrel{\Rightarrow}{0}$ \\
\hline 案 & . & 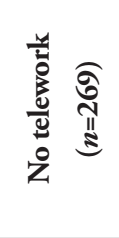 &.$\frac{60}{\omega}$ & $\begin{array}{l}\text { 齐 } \\
\text { i }\end{array}$ & $\vec{\delta}$ & 类 & $\begin{array}{l}\stackrel{0}{\hat{Q}} \\
\hat{i}\end{array}$ & 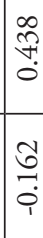 & $\begin{array}{l}\text { సิ } \\
\text { î }\end{array}$ & $\begin{array}{c}n \\
\tilde{n} \\
0 \\
0\end{array}$ & 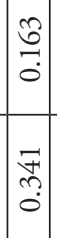 & $\mid \begin{array}{l}0 \\
0 \\
0 \\
0\end{array}$ & 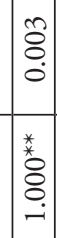 & 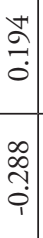 & 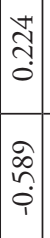 & 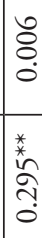 & $\mid \begin{array}{l}\tilde{0} \\
\hat{0} \\
0\end{array}$ & ' & 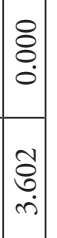 & $\frac{\pi}{0}$ & & & $\stackrel{*}{*}$ & $\Xi$ \\
\hline 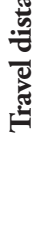 & $\bar{z}$ & 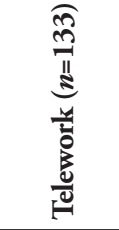 & .00 & $\stackrel{\frac{\hat{\sigma}}{0}}{\frac{1}{0}}$ & 总 & 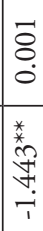 & $\stackrel{0}{0}$ & $\begin{array}{l}\stackrel{0}{0} \\
\stackrel{2}{0}\end{array}$ & $\begin{array}{l}\tilde{N} \\
\stackrel{\tilde{i}}{\mathbf{i}}\end{array}$ & 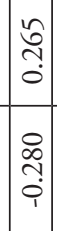 & 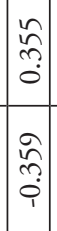 & 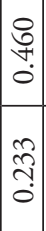 & 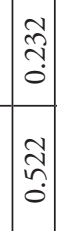 & $\begin{array}{l}m \\
\overrightarrow{7} \\
\vdots \\
i\end{array}$ & $\mid \begin{array}{c}\hat{N} \\
0 \\
0 \\
0\end{array}$ & & י & I & 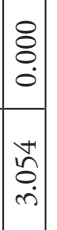 & $y^{2}$ & & & ' & \\
\hline & 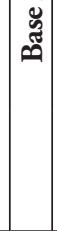 & 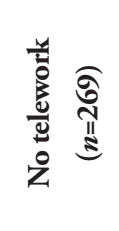 & $\frac{.000}{m}$ & & $\mid \begin{array}{l}\infty \\
\hat{n} \\
\hat{0}\end{array}$ & 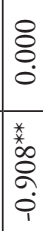 & 궁 & 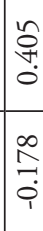 & $\stackrel{ }{\stackrel{1}{-}}$ & $\mid \begin{array}{c}0 \\
0 \\
0 \\
0\end{array}$ & \begin{tabular}{|c|}
$\vec{n}$ \\
$\tilde{n}$ \\
$\vec{n}$ \\
$\tilde{n}$ \\
$\tilde{0}$
\end{tabular} & $\mid \begin{array}{l}+ \\
\infty \\
\infty \\
0 \\
0\end{array}$ & \begin{tabular}{l}
$*$ \\
\multirow{4}{*}{} \\
0 \\
0 \\
0 \\
0
\end{tabular} & 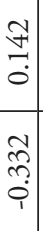 & 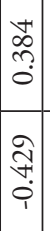 & & & I & 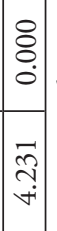 & $0^{\circ}$ & & & & \\
\hline
\end{tabular}

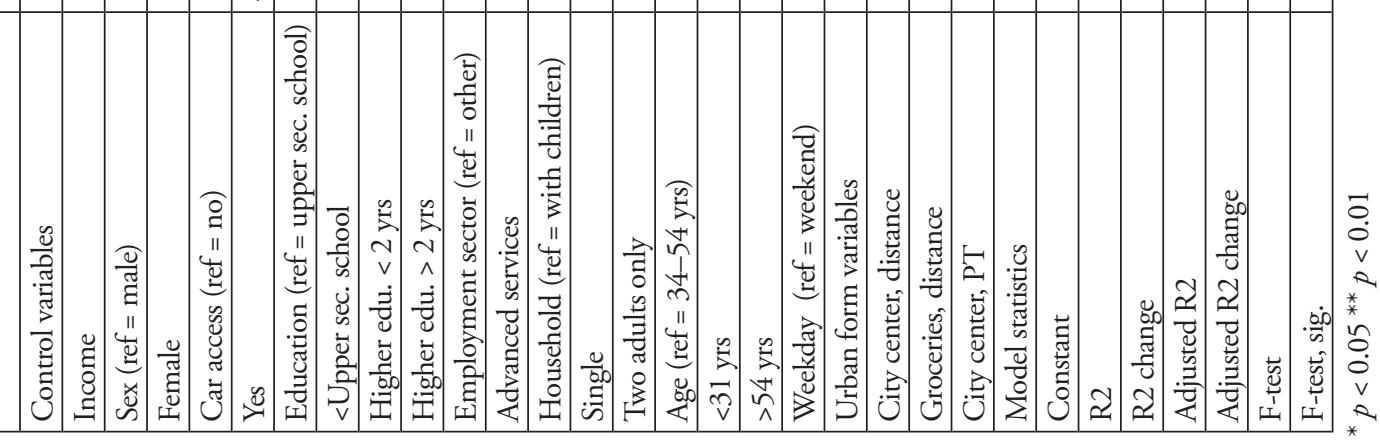




\section{$5 \quad$ Conclusions and discussion}

This paper has revisited past literature on the influence of urban form on daily travel behavior. The distance and duration of work trips and daily travel, especially on workdays, have previously been found to be strongly influenced by urban structure (Elldér 2014b; Næss 2005). Comparison between teleworkers and non-teleworkers, however, indicates that teleworking weakens the relationships between urban form and travel behavior on workdays. Regression models measuring the total travel distance and time during actual workdays as results of various aspects of urban structure relative to residential location display better fit for those not teleworking regularly. In fact, the urban form variables explain little of the variation in travel time and distance and retain few significant effects when fitting the models only for those who teleworked on the actual survey day.

One potential explanation for this concerns differences in work-related travel between the groups compared. For regular workers, commuting generally accounts for most travel on workdays and is usually tied to a certain workplace. The spatial patterns of travel and destination choices are anchored to both the home and work locations and are, therefore, strongly spatially fixed. The strong effect of residential location relative to the city center attests to this. Many workplaces in Gothenburg's urban region are located within or near the city center. This spatial fixity is possibly relaxed when workers can telework and are anchored only to their residential location. This may afford opportunities for freer planning of daily activities in space and time based on individual needs and wishes, independent of the work location. For example, some workers might use the mobility resources saved to reach more distant non-work destinations, while others may decide to reduce their traveling or choose slower modes of transportation, and some may work at their regular workplace for only parts of the day. Another possibility is that telework allows more people to remain in or move to places with poor physical access; in these cases, the residential location might be important for more personal reasons. Telework allows for a broader spectrum of individual mobility strategies that together contribute to more spatially heterogeneous daily travel behavior, possibly often more dependent on who one is than where one lives relative to one's workplace. It is, however, important to emphasize that the groups of workers compared in this study are not only different in terms of teleworking practices but also to some extent in other aspects. An important task for future research is to apply experimental research designs to confirm the results presented and more thoroughly estimate the causal effect of telework on urban structure-travel relationships.

Additional aspects of the results also merit discussion. First, travel time is not as strongly linked to urban form as is travel distance, partly due to spatial variations in mode choice. Slower transportation modes are more frequently used by those who live more centrally, which levels the spatial differences in travel time. Inter-group differences regarding the influence of urban form, however, are similar to intergroup differences regarding the travel distance models. Furthermore, although this paper did not set out to analyze the variables for individual characteristics, some results should be borne in mind, particularly from policy and planning perspectives. Consistent with many previous studies (e.g., Ewing and Cervero 2001), the individual variables explain more variation in travel distance than do the urban form variables. Of these individual variables, car access is, as expected, a key determinant of how far people travel on workdays - regardless of whether or not one adds urban form variables or considers teleworkers/ non-teleworkers. These results are also consistent with those of previous research.

Although the present results are consistent with the hypothesis that teleworking leads to more spatially heterogeneous travel patterns, several important issues remain for future research to explore. The results only apply to workers who travel on the day of the survey. Only 2-3 percent of the sample reported no trips, and these people were not included in the analysis. Since it is not unusual that travel surveys include larger shares of people not reporting any trips, this, however, might be of greater impor- 
tance in future studies. Furthermore, recent research has acknowledged the difference between telework for the entire workday versus parts of it (Haddad, Lyons, and Chatterjee 2009). In this case, many of the respondents ( 60 percent) reported work-related travel during teleworking days indicating part-day teleworking and may be contributing to the differences in urban structure-travel relationships. If allowed by data used in future research, it would be interesting to examine differences between whole-day and part-day teleworkers.

Another related and important example concerns the single-day survey design, which does not allow drawing conclusions about possible inter-day dependencies of the spatiotemporal flexibility of activities. As discussed, telework might allow working or living at remote places with implications for travel behavior aggregated over a longer period of time. In addition several potential motives for telework impossible to derive from the travel survey data have implications for the relationship between urban form and travel. It is difficult to fully understand people's travel habits relative to spatial factors and teleworking practices without comprehensive knowledge of individuals' (and other household members') daily time-use practices. This is probably an important explanation of the low $\mathrm{R}^{2}$ values in the travel-time models and indicates the importance of research specifically designed to deepen our understanding of this matter. For example, one could survey how daily mobility and destination choices relative to urban structure change after a person starts teleworking. It would also be interesting to design studies to examine whether the present results are generalizable to other forms of ICT use, trip purposes, and population groups. It is also important to test whether the differences between teleworkers and non-teleworkers observed in the Gothenburg case are similar in other geographical contexts. For example, one main explanation for the in some cases strong effects of the distance to the city center is the monocentric urban structure of Gothenburg. It is important to also analyze polycentric city regions and evaluate whether the results differ in such contexts. The recent increase in teleworking in many countries should allow for similar studies.

Finally, it is important to emphasize that these questions are developing rapidly at the moment, not only because teleworking is growing, but also because ICT technologies are continuing their rapid development. Planners and policymakers should keep a close eye on whether the number of teleworkers continues to increase. In such a scenario, results suggest that traditional distance- and location-based models and policies for predicting and planning transportation may prove less accurate and effective than currently assumed. The high flows of daily travel between residential and workplace clusters would then be likely to thin out. Often-prioritized land-use policies, for example, emphasizing mixed development and job-housing balance, might then gradually lose their effectiveness. Furthermore, other external factors could modify these relationships in the future; for example, increased travel costs would make people more spatially fixed. In such a case, a larger substitution potential of telework could be realized. It is safe to say that this important and rapidly changing area will continue to merit study in the future.

\section{Acknowledgements}

The author would gratefully like to acknowledge the insightful and valuable comments provided by the anonymous referees. Thanks also to Bertil Vilhelmson, the members of the Mobility Research Group at the Human Geography unit, University of Gothenburg, and visiting professor Masaki Kawase, Hiroshima Shudo University, for helpful comments on earlier versions of this paper. 


\section{References}

Andreev, P., I. Salomon, and N. Pliskin. 2010. Review: State of tele-activities. Transportation Research Part C: Emerging Technologies 18(1): 3-20.

Banister, D. 2011. The trilogy of distance, speed and time. Journal of Transport Geography 19(4): 950959.

Boarnet, M. G. 2011. A broader context for land use and travel behavior, and a research agenda. Journal of the American Planning Association 77(3): 197-213.

Cervero, R. 1989. Jobs-housing balancing and regional mobility. Journal of the American Planning Association 55(2): 136-150.

Cervero, R., and K. Kockelman. 1997. Travel demand and the 3Ds: Density, diversity, and design. Transportation Research Part D: Transport and Environment 2(3): 199-219.

Couclelis, H. 2000. From sustainable transportation to sustainable accessibility: Can we avoid a new tragedy of the commons? In Information, Place and Cyberspace, edited by D. G. Janelle and D. C. Hodge, 341-356. Berlin: Springer.

Elldér, E. 2014a. Commuting choices and residential built environments in Sweden, 1990-2010: A multilevel analysis. Urban Geography 35(5): 715-734.

Elldér, E. 2014b. Residential location and daily travel distances: The influence of trip purpose. Journal of Transport Geography 34: 121-130.

Ewing, R., and R. Cervero. 2001. Travel and the built environment: A synthesis. Transportation Research Record 1780: 87-113.

Ewing, R., and R. Cervero. 2010. Travel and the built environment. Journal of the American Planning Association 76(3): 265-294.

Farag, S., and G. Lyons. 2010. Explaining public transport information use when a car is available: Attitude theory empirically investigated. Transportation 37(6): 897-913.

Frändberg, L., and B. Vilhelmson. 2014. Spatial, generational and gendered trends and trend-breaks in mobility. In Handbook of Sustainable Travel, edited by T. Gärling, D. Ettema, and M. Friman, 15-32. Dordrecht: Springer.

Haddad, H., G. Lyons, and K. Chatterjee. 2009. An examination of determinants influencing the desire for and frequency of part-day and whole-day homeworking. Journal of Transport Geography 17(2): 124-133.

Helling, A., and P. L. Mokhtarian. 2001. Worker telecommunication and mobility in transition: Consequences for planning. Journal of Planning Literature 15(4): 511-525.

Helminen, V., and M. Ristimäki. 2007. Relationships between commuting distance, frequency and telework in Finland. Journal of Transport Geography 15: 331-342.

Hopkinson, P., and P. James. 2003. UK report on national SUSTEL fieldwork. Report no. SUSTEL IST-2001-33228. URL: http://webfarm.userve.net/-flexiworker/pdf/Case\%20studies.pdf

Jones, P. M. 1983. Understanding Travel Behavior. Aldershot, UK: Gower.

Kwan, M.-P. 2002. Time, information technologies, and the geographies of everyday life. Urban Geography 23(5): 471-482.

Kwan, M.-P., M. Dijst, and T. Schwanen. 2007. The interaction between ICT and human activitytravel behavior. Transportation Research Part A: Policy and Practice 41(2): 121-124.

Kwan, M.-P., and J. Weber. 2003. Individual accessibility revisited: Implications for geographical analysis in the 21st century. Geographical Analysis 35(4): 341-353.

Larsson, A., E. Elldér, and B. Vilhelmson. 2014. Accessibility Atlas to analyze regional accessibility to labor in the food sector. In COST Action TU1002-Assessing Usability of Accessibility Instruments, 
edited by M. Brömmelstroet, C. Silva, and L. Bertolini, 115-121. Amsterdam: European Cooperation In Science and Technology, COST Office.

Lenz, B., and C. Nobis. 2007. The changing allocation of activities in space and time by the use of ICT-Fragmentation as a new concept and empirical results. Transportation Research Part A: Policy and Practice 41(2): 190-204.

Lu, R., C. G. Chorus, and B. van Wee. 2012. The effects of different forms of ICT on accessibility: A behavioral model and numerical examples. Transportmetrica A: Transport Science 10(3): 233-254.

Lyons, G. 2009. The reshaping of activities and mobility through new technologies. Journal of Transport Geography 17(2): 81-82.

Miller, H. 2007. Place-based versus people-based geographic information science. Geography Compass 1(3): 503-535.

Mokhtarian, P. L., and G. Tal. 2013. Impacts of ICT on travel behavior: A tapestry of relationships. In The Sage Handbook of Transport Studies, edited by J. P. Rodrigue, T. Notteboom, and J. Shaw, 241-260. London: SAGE Publications.

Mokhtarian, P. L., G. O. Collantes, and C. Gertz. 2004. Telecommuting, residential location, and commute-distance traveled: Evidence from state of California employees. Environment and Planning A 36(10): 1877-1897.

Mokhtarian, P. L., and K. V. Varma. 1998. The trade-off between trips and distance traveled in analyzing the emissions impacts of center-based telecommuting. Transportation Research Part D: Transport and Environment 3(6): 419-428.

Næss, P. 2005. Residential location affects travel behavior-but how and why? The case of Copenhagen metropolitan area. Progress in Planning 63(2): 167-257.

Næss, P. 2011. New urbanism or metropolitan-level centralization? A comparison of the influences of metropolitan-level and neighborhood-level urban form characteristics on travel behavior. Journal of Transport and Land Use 4(1): 25-44.

Næss, P. 2013. Residential location, transport rationales and daily-life travel behavior: The case of Hangzhou Metropolitan Area, China. Progress in Planning 79: 1-50.

Pendyala, R., K. Goulias, and R. Kitamura. 1991. Impact of telecommuting on spatial and temporal patterns of household travel. Transportation 18(4): 383-409.

Salomon, I. 1986. Telecommunications and travel relationships: A review. Transportation Research Part A: General 20(3): 223-238.

Saxena, S., and P. Mokhtarian. 1997. The impact of telecommuting on the activity spaces of participants. Geographical Analysis 29(2): 124-144.

SCB. 2011. Longitudinell integrationsdatabas for Sjukförsäkrings- och Arbetsmarknadsstudier (LISA) 1990-2009. Stockholm: SCB.

Schwanen, T., M.-P. Kwan, and F. Ren. 2008. How fixed is fixed? Gendered rigidity of space-time constraints and geographies of everyday activities. Geoforum 39(6): 2109-2121

Stead, D., and S. Marshall. 2001. The relationship between urban form and travel patterns: An international review and evaluation. European Journal of Transport and Infrastructure Research 1(2): 113-141. Trafikanalys. 2012. Metodrapport RVU Sverige 2011. Report no. PM 2012:8. Stockholm: Trafikanalys. van Wee, B., K. Geurs, and C. Chorus. 2013. Information, communication, travel behavior and accessibility. Journal of Transport and Land Use 6(3): 1-16.

Vilhelmson, B., and E. Thulin. 2001. Is regular work at fixed places fading away? The development of ICT-based and travel-based modes of work in Sweden. Environment and Planning A 33(6): 10151030. 
Vilhelmson, B., and E. Thulin. 2008. Virtual mobility, time use, and the place of the home. Tijdschrift voor Economische en Sociale Geografie 99(5): 602-618.

Vilhelmson, B., and E. Thulin. 2015. Who and where are the flexible workers? Exploring the current diffusion of telework in Sweden. Submitted manuscript.

Wener, R., G. Evans, D. Phillips, and N. Nadler. 2003. Running for the 7:45: The effects of public transit improvements on commuter stress. Transportation 30(2): 203-220. 


\begin{tabular}{|c|c|c|c|c|c|c|c|c|c|c|c|c|c|c|c|}
\hline 茎 & \begin{tabular}{l}
$*$ \\
$*$ \\
\multirow{2}{*}{} \\
$i$ \\
$i$
\end{tabular} & $\mid$\begin{tabular}{c}
$*$ \\
\multirow{2}{*}{} \\
$\stackrel{2}{\grave{T}}$ \\
1 \\
1
\end{tabular} & $\underset{i}{\stackrel{*}{*}}$ & 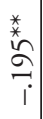 & 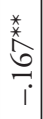 & $\begin{array}{l}\stackrel{*}{*} \\
\stackrel{\infty}{\infty} \\
i\end{array}$ & $\begin{array}{c}* \\
0 \\
0 \\
7 \\
1 \\
1\end{array}$ & 总 & $\stackrel{*}{\stackrel{*}{\infty}} \underset{i}{=}$ & $\stackrel{*}{\stackrel{*}{*}}$ & 苦 & 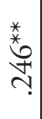 & $\begin{array}{l}+ \\
\vdots \\
0 \\
0\end{array}$ & & - \\
\hline 宊 & 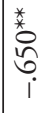 & $\left|\begin{array}{c}* \\
\multirow{2}{*}{} \\
0 \\
0 \\
0 \\
1 \\
1\end{array}\right|$ & 䔍 & 密 & 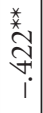 & 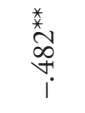 & 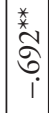 & 蓠 & 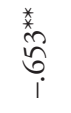 & $\stackrel{*}{\stackrel{*}{*}}$ & $\stackrel{*}{\stackrel{*}{*}} \stackrel{2}{\stackrel{*}{*}}$ & 类 & 息 & - & \\
\hline 玄 & $\mid$\begin{tabular}{l}
$*$ \\
\multirow{*}{*}{} \\
$\infty$ \\
$\infty$ \\
$i$ \\
$i$ \\
$i$
\end{tabular} & \begin{tabular}{c}
$*$ \\
\multirow{2}{*}{} \\
0 \\
0 \\
1 \\
1
\end{tabular} & 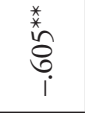 & 蒌 & $\stackrel{*}{*}$ & $\stackrel{*}{*}$ & $\stackrel{*}{\underset{*}{*}} \underset{i}{\stackrel{*}{N}}$ & 蒫 & $\underset{i}{\stackrel{*}{*}}$ & $\stackrel{*}{\stackrel{*}{*}}$ & کั* & $\stackrel{*}{\stackrel{*}{*}} \stackrel{.}{*}$ & - & & \\
\hline$\stackrel{n}{\xi}$ & 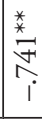 & 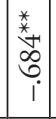 & $\underbrace{\stackrel{*}{*}}_{i}$ & 苦 & 悉 & \begin{tabular}{l}
$*$ \\
\multirow{6}{*}{} \\
$i$ \\
$i$
\end{tabular} & \begin{tabular}{c}
$*$ \\
\multirow{*}{*}{} \\
\multirow{2}{*}{} \\
$i$ \\
$i$
\end{tabular} & 苾 & 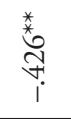 & 类 & 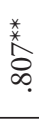 & - & & & \\
\hline$\hat{n}$ & \begin{tabular}{|c|c}
$*$ \\
$*$ \\
0 \\
$\infty$ \\
$\infty$ \\
$i$ \\
1
\end{tabular} & 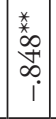 & 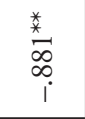 & $\begin{array}{l}* \\
* \\
0 \\
0 \\
i \\
\end{array}$ & \begin{tabular}{c}
$\stackrel{*}{*}$ \\
\multirow{2}{F}{} \\
$i$ \\
\end{tabular} & $\stackrel{*}{*}$ & $\begin{array}{c}* \\
i \\
0 \\
0 \\
0 \\
i \\
\end{array}$ & 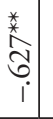 & 藁 & 卷 & - & & & & \\
\hline$\stackrel{n}{\stackrel{0}{0}}$ & $\begin{array}{c}* \\
0 \\
0 \\
\infty \\
i \\
1\end{array}$ & 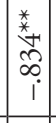 & 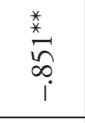 & 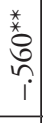 & 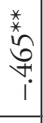 & 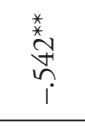 & $\stackrel{*}{*}$ & \begin{tabular}{l}
$*$ \\
\multirow{2}{*}{} \\
$\hat{\sigma}$ \\
$i$ \\
$i$
\end{tabular} & $\underset{i}{*}$ & - & & & & & \\
\hline 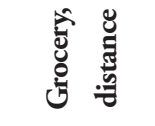 & . & 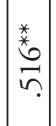 & 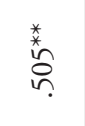 & 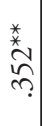 & $\mid$ & $\begin{array}{l}\frac{*}{*} \\
\infty \\
\infty\end{array}$ & 躴 & 蒾 & - & & & & & & \\
\hline 总 & 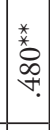 & 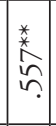 & 恙 & 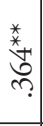 & 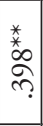 & $\begin{array}{l}\stackrel{*}{*} \\
\stackrel{\infty}{\infty} \\
m\end{array}$ & $\left|\begin{array}{l}* \\
0 \\
\infty \\
\infty \\
\infty \\
\infty\end{array}\right|$ & - & & & & & & & \\
\hline है & 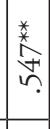 & $\left|\begin{array}{l}* \\
* \\
\infty \\
\infty \\
? \\
?\end{array}\right|$ & 蒾 & 悉 & 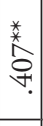 & \begin{tabular}{l}
\multirow{*}{*}{} \\
\multirow{\Im}{*}{}
\end{tabular} & $\neg$ & & & & & & & & \\
\hline 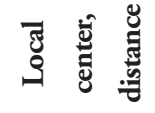 & 悉 & 絭 & 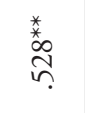 & 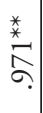 & 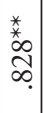 & - & & & & & & & & & \\
\hline 总离至 & 类 & . & 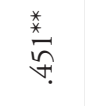 & 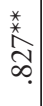 & - & & & & & & & & & & \\
\hline 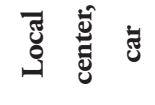 & 絭 & 苗 & $\stackrel{*}{\stackrel{*}{n}}$ & - & & & & & & & & & & & \\
\hline 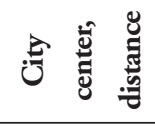 & 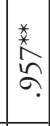 & ڤ. & - & & & & & & & & & & & & \\
\hline 氖离比 & 絭 & - & & & & & & & & & & & & & \\
\hline ङ & - & & & & & & & & & & & & & & \\
\hline & 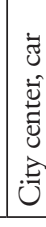 & 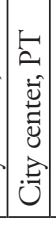 & 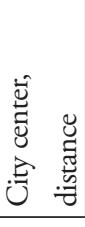 & 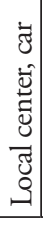 & 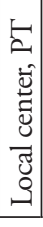 & 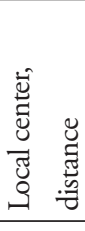 & 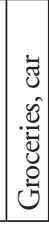 & 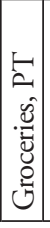 & 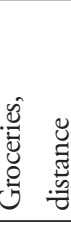 & 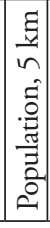 & \begin{tabular}{|l} 
\\
\\
$\frac{g}{n}$ \\
$n$ \\
0 \\
0 \\
0
\end{tabular} & $\begin{array}{l}\xi \\
\frac{z}{n} \\
z \\
z \\
z\end{array}$ & $\underline{G}$ & & 焉 \\
\hline
\end{tabular}

